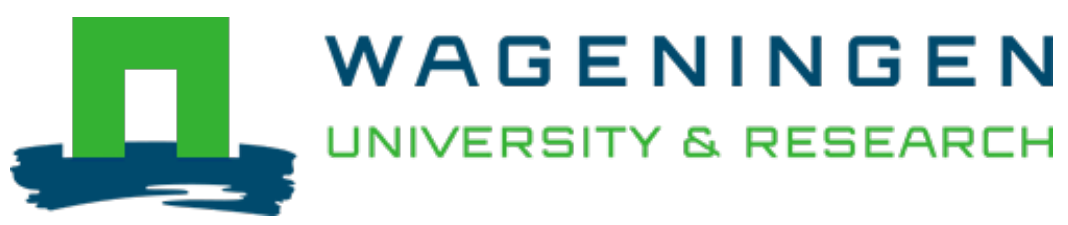

\author{
Scaling relationships among functional traits are similar across individuals, \\ species, and communities \\ Journal of Vegetation Science \\ Long, Wenxing; Zhou, Yadong; Schamp, Brandon S.; Zang, Runguo; Yang, Xiaobo et al \\ https://doi.org/10.1111/jvs.12893
}

This publication is made publicly available in the institutional repository of Wageningen University and Research, under the terms of article $25 \mathrm{fa}$ of the Dutch Copyright Act, also known as the Amendment Taverne. This has been done with explicit consent by the author.

Article 25 fa states that the author of a short scientific work funded either wholly or partially by Dutch public funds is entitled to make that work publicly available for no consideration following a reasonable period of time after the work was first published, provided that clear reference is made to the source of the first publication of the work.

This publication is distributed under The Association of Universities in the Netherlands (VSNU) 'Article $25 \mathrm{fa}$ implementation' project. In this project research outputs of researchers employed by Dutch Universities that comply with the legal requirements of Article $25 \mathrm{fa}$ of the Dutch Copyright Act are distributed online and free of cost or other barriers in institutional repositories. Research outputs are distributed six months after their first online publication in the original published version and with proper attribution to the source of the original publication.

You are permitted to download and use the publication for personal purposes. All rights remain with the author(s) and / or copyright owner(s) of this work. Any use of the publication or parts of it other than authorised under article $25 \mathrm{fa}$ of the Dutch Copyright act is prohibited. Wageningen University \& Research and the author(s) of this publication shall not be held responsible or liable for any damages resulting from your (re)use of this publication.

For questions regarding the public availability of this publication please contact openscience.library@wur.nl 


\title{
Scaling relationships among functional traits are similar across individuals, species, and communities
}

\author{
Wenxing Long $^{1,2}$ | Yadong Zhou ${ }^{3}$ | Brandon S. Schamp ${ }^{4}$ (i) | Runguo Zang ${ }^{5,6}$ | \\ Xiaobo Yang $^{7}$ | Lourens Poorter $^{8}$ | Chuchu Xiao ${ }^{1,2}$ | Menghui Xiong ${ }^{9}$
}

\footnotetext{
${ }^{1}$ College of Forestry/Wuzhishan National Long-Term Forest Ecosystem Monitoring Research Station, Hainan University, Haikou, P. R. China

${ }^{2}$ Key Laboratory of Genetics and Germplasm Innovation of Tropical Special Forest Trees and Ornamental Plants (Hainan University), Ministry of Education, College of Forestry, Hainan University, Haikou, P. R. China

${ }^{3}$ Forestry Bureau of Hainan Province, Haikou, P. R. China

${ }^{4}$ Department of Biology, Algoma University, Sault Ste. Marie, ON, Canada

${ }^{5}$ Key Laboratory of Forest Ecology and Environment of the State Forestry and Grassland Administration, Research Institute of Forest Ecology, Environment and Protection, Chinese Academy of Forestry, Beijing, P. R. China

${ }^{6}$ Co-Innovation Center for Sustainable Forestry in Southern China, Nanjing Forestry University, Nanjing, P. R. China

${ }^{7}$ College of Ecology and Environment, Hainan University, Haikou, P. R. China

${ }^{8}$ Forest Ecology and Forest Management Group, Wageningen University and Research, Wageningen, The Netherlands

${ }^{9}$ Agricultural and Rural Bureau of Pengshan District, Meishan, P. R. China
}

\section{Correspondence}

Brandon S. Schamp, Department of Biology, Algoma University, Sault Ste. Marie, Ontario, P6A 2G4 Canada.

Email: brandon.schamp@algomau.ca

Runguo Zang, Key Laboratory of Forest Ecology and Environment of State Forestry Administration; Institute of Forest Ecology, Environment and Protection, Chinese Academy of Forestry, Beijing 100091, China. Email: zangrung@caf.ac.cn

Funding information

National Natural Science Foundation of China (Grant 31660163, 31870508 and 31260109), Innovative Research Team grant of the Natural Science Foundation of Hainan Province (2016CXTD003), Natural Science Foundation of Hainan Province (Grant 312064) and Natural Sciences and Engineering Council of Canada to Brandon S. Schamp (RGPIN-2015-04397).

Co-ordinating Editor: Zeleny

\begin{abstract}
Question: Bivariate relationships among functional traits reflect how plants adjust to environments through the allocation of limiting resources. Bivariate relationships are well studied across species, but whether the nature of these trait relationships changes across organizational levels (individual, species, community), and whether processes driving these relationships vary across these levels, is seldom explored.

Location: The tropical cloud forests of the Bawangling Nature Reserve, Jianfengling Nature Reserve and Limushan Nature Reserve on Hainan Island, Southern China.

Methods: We measured leaf mass per area (LMA), plant height $(\mathrm{H})$ and wood density (WD) for 4,748 individual trees, 174 species and 48 communities in three tropical cloud forests, and recorded five soil characteristics that are important for plant growth. We evaluated bivariate relationships between these traits across the three organizational levels, and assessed the effects of soil conditions on these trait relationships.

Results: LMA versus $H, W D$ versus $H$, and LMA versus WD were all positively and disproportionately related, suggesting differential carbon investment between leaves and stem, as well as between stem height and stem density. The slopes of these relationships did not differ significantly across the three levels, suggesting a similar allocation strategy operating at different hierarchical levels. Soil phosphorus had a significant effect on the scaling exponents across all three organizational levels, indicating that phosphorus limitation in cloud forests is a principal driver of resource allocation patterns in trees.
\end{abstract}


Conclusions: We conclude that tropical cloud forest trees have relatively consistent scaling relationships between three primary functional traits across the individual, species, and community levels. The coordinated resource allocation strategies in plants are most likely driven by the prevailing environmental constraints.

\section{KEYWORDS}

bivariate trait relationships, environmental stress, leaf mass per area, plant height, plant strategy, soil phosphorus, tropical forest, wood density

\section{$1 \mid$ INTRODUCTION}

In environments with limited resources, plants generally employ strategies to optimize the allocation of resources to different functional traits (Price and Weitz, 2012) and increase growth, survival, and reproduction in a given environment (Reich et al., 1997; Westoby, 1998; Fonseca et al., 2000; Wright et al., 2004; Chave et al., 2009; Onoda et al., 2011; Díaz et al., 2016). Such allocation strategies can be explored by assessing the slope of bivariate trait relationships (Wright et al., 2004). A slope that significantly differs from +1.0 or -1.0 (i.e., disproportionate relationships, log scale) indicates that plants disproportionately allocate resources to specific plant functions.

Studies indicate that there are disproportionate scaling relationships among many leaf traits (e.g., LMA, leaf life span, leaf nitrogen concentration, photosynthetic capacity; Reich et al., 1997; Wright et al., 2004; Onoda et al., 2011; Xiang et al., 2013, etc.), and wood traits (e.g., wood density, conduit diameter, sapwood area conductivity; Chave et al., 2009). Recently Díaz et al. (2016) found that trait space occupied by global vascular plants is coordinated and characterized by trade-offs among six traits critical to growth, survival and reproduction. However, these patterns have largely been assessed among species, typically using species mean values (Reich et al., 1997; Wright et al., 2004; Xiang et al., 2013; Díaz et al., 2016). Moreover, comparative studies suggest that in many instances, intraspecific trait variation is comparable to interspecific variation (Albert et al., 2010; Bolnich et al., 2011; Laforest-Lapointe et al., 2014; Siefert et al., 2015), and that intraspecific trait variation can promote species coexistence by enabling species to pass through a broader range of environmental filters (Long, Zang, Schamp, et al., 2011). For example, including intraspecific trait variation can be consequential in tests for significant trait overdispersion among coexisting plant species (e.g., de Bello et al., 2013; Jensen et al., 2019).

In addition to disproportionate scaling relationships at the species and within-species levels, Reich (2014) has proposed that these relationships also exist at the community and ecosystem level. Recent studies demonstrate that community-weighted mean trait values (CWM) can be used to relate functional composition to environmental conditions (Swenson and Weiser, 2010), allowing researchers to examine which environmental filters may drive community assembly (Ackerly et al., 2002; Long, Zang, and Ding, 2011 Domínguez et al., 2012). Our approach of examining these bivariate relationships at three hierarchical levels allows us to test whether important scaling relationships observed elsewhere are present at the within-species and community levels, whether those bivariate relationships are similar across levels, and whether observed bivariate relationships are influenced similarly by abiotic gradients across the three levels considered (Castro-Díez, 2012; Messier et al., 2017).

Bivariate trait scaling relationships across the individual, species, and community levels can be influenced by genetic effects, plant developmental stages, physiological or biomechanical constraints, plasticity, selective pressure (or species sorting/filtering), ecosystem types, and disturbance (Vasseur et al., 2012; Wright and SuttonGrier, 2012; Xiang et al., 2013). For example, the interspecific scaling relationships among key leaf traits (morphological, chemical, and metabolic) result from a synergy between physiological, biophysical and evolutionary constraints on leaf phenotypes for species in any terrestrial ecosystem (Field and Mooney, 1986; Díaz et al., 2016). At the individual level, phenotypic plasticity allows plants to adjust their physiological and structural attributes to better match different environmental conditions. Conversely, community-weighted mean trait values, which are closely related to individual plant abundance and species turnover rates (Cornwell and Ackerly, 2009; Castro-Díez, 2012), may exhibit trait relationships that differ from those observed in within- and among-species analyses. This may be due to the effects of environmental filtering, which some evidence suggests is more conspicuous at the community level (Ackerly et al., 2002; Swenson and Weiser, 2010; Domínguez et al., 2012).

Tropical cloud forests experience a unique combination of abiotic conditions that distinguish them from low-altitude tropical forests (Long, Ding, et al., 2011). These abiotic conditions strongly impact trait values of individuals, species, and communities (Long, Zang, and Ding, 2011; Long, Zang, Schamp, et al., 2011) and affect species distributions and community assembly (Long, Schamp, et al., 2015). For example, research has demonstrated that facilitative interactions in tropical cloud forests play a role in tree species assembly and coexistence in the face of important abiotic stresses such as low soil nutrient availability and high winds (Long et al., 2013; Long, Schamp, et al., 2015). It is likely that these same abiotic conditions shape resource allocation strategies at within-species, among-species, and community levels.

We measured three functional traits, leaf mass per area (LMA), plant height $(\mathrm{H})$ and wood density (WD); all three are important for plant growth and survival and capture the main strategy axes of 
variation. LMA is the leaf dry mass divided by the one-sided area of a fresh leaf and reflects a plant's allocation of resources in leaves (Wright et al., 2004; Poorter et al., 2009). H reflects the ability of a plant to compete for light and space (Long, Schamp, et al., 2015), and is related to a plant's carbon acquisition strategy (Falster and Westoby, 2003). WD, the dry mass per fresh volume of the stem, is often associated with plant stability and defense, and is recognized as a core functional trait (Chave et al., 2009). These three key traits were measured for 4,748 trees belonging to 174 species and 48 community plots in three Chinese tropical cloud forests.

In this paper, we examine: (a) what bivariate trait relationships are found across three key traits, (b) whether these scaling relationships are similar across three hierarchical levels (individuals, species and communities); and (c) to what extent these relationships are shaped by important soil nutrients. Finally, because the functional traits we examine here contribute to important resource allocation strategies among plant species, we tested whether the slopes of bivariate relationships among all three traits would be conserved (i.e., consistent) across the three hierarchical levels.

\section{2 | METHODS}

\section{1 | Study sites}

This study was conducted in the tropical cloud forests of the Bawangling Nature Reserve (BNR), Jianfengling Nature Reserve (JNR) and Limushan Nature Reserve (LNR) on Hainan Island, Southern China. These three forest reserves are composed of undisturbed old-growth forest, mainly distributed as mountaintop islands at altitudes greater than $1,250 \mathrm{~m}$. The rainy season ranges from May to October and the dry season ranges from November to April of the next year. Soils are montane meadow soils developed from sandstone, with inclinations ranging from $3^{\circ}$ to $65^{\circ}$. These forests are characterized by low air temperature, strong winds and frequent fog; consequently, trees in these forests are frequently deformed and short in stature. Average tree height is $4.8 \mathrm{~m} \pm 2.8 \mathrm{~m}$ (BNR), $4.1 \mathrm{~m} \pm 2.2 \mathrm{~m}(\mathrm{JNR})$ and $5.3 \mathrm{~m} \pm 3.4 \mathrm{~m}$ (LNR) and tree densities were 9,633 stems ha ${ }^{-1}, 2,577$ stems ha ${ }^{-1}$ and 6,325 stems ha ${ }^{-1}$ respectively (for all trees with $\mathrm{DBH}$ [diameter at breast height] $\geq 1 \mathrm{~cm}$ ). The five most abundant tree species across the three reserves are Distylium racemosum Siebold \& Zucc., Syzygium buxifolium Hook. \& Arn., Xanthophyllum hainanense Hu, Camellia sinensis (L.) O. Ktze. var. assamica (J.W.Mast.) Kitam. and Cyclobalanopsis championii (Benth.) Oerst. (Appendix S1).

\section{2 | Data collection}

We collected data from randomly located $20 \mathrm{~m} \times 20 \mathrm{~m}$ plots in tropical cloud forests (BNR: 21 plots; JNR: 12 plots; LNR: 15 plots). The distance between any two plots was always greater than $50 \mathrm{~m}$ and the total plot area spanned 1.92 ha across the three sites. The different number of plots in each site reflects the fact that the three study sites differ in overall area. Before vegetation surveys were completed, each 400- $\mathrm{m}^{2}$ plot was divided into $410 \mathrm{~m} \times 10 \mathrm{~m}$ subplots and $165 \mathrm{~m} \times 5 \mathrm{~m}$ quadrats. We measured the height of all individual trees appearing in the study plots with $\mathrm{DBH} \geq 5 \mathrm{~cm}$ using a clinometer. Measurements excluded stems that were clearly suckering from other trees, and when a dominant stem was less clear, the tallest sucker/stem was measured. Taxonomic identification was in accordance with Flora Reipublicae Popularis Sinicae (Editorial Committee of Flora of China, 2004). A total of 4,748 individual trees representing 174 species were recorded (BNR: 76 species, JNR: 121 species, LNR: 80 species).

The relatively small stature of trees in the three study forests helped us to accurately measure H, WD and LMA for each of the 4,748 trees in our plots during the rainy season from July to August, 2013 (following the protocol of Pérez-Harguindeguy et al., 2013). These functional traits were chosen to reflect the ways that plants grow and survive (Wright et al., 2004; Chave et al., 2009; Poorter et al., 2009; Baraloto et al., 2010; Onoda et al., 2011). For example, LMA is the dry mass divided by the one-sided area of a fresh leaf; variation in LMA is understood to reflect how different species allocate resources to the production of leaves (Wright et al., 2004; Poorter et al., 2009). LMA is also related to a plant's ability to obtain nutrients and change growth rate (Castro-Díez, 2012). $\mathrm{H}$ is the shortest distance from the base of the plant stem to the highest sucker/ shoot in the canopy, reflecting the ability of a plant to compete for light and space (Long, Schamp et al., 2015), and is therefore related to carbon acquisition strategy (Falster and Westoby, 2003). WD is the dry mass per fresh volume of the stem. It is often associated with plant stability and defense and is therefore recognized as a core functional trait (Chave et al., 2009). Exploring bivariate relationships among these traits is expected to improve our understanding plants resource allocation in tropical cloud forests.

To determine leaf traits, we collected and measured three recently expanded sun leaves (current year's growth) from each individual plant $\left(\mathrm{DBH} \geq 5 \mathrm{~cm}\right.$ ) in each $400-\mathrm{m}^{2}$ plot. Leaf area was quantified using a leaf area meter (LI-COR $3100 \mathrm{C}$ Area Meter, LICOR). Leaves were then dried to a constant weight at $70^{\circ} \mathrm{C}$ for at least three days and weighed to the nearest $0.01 \mathrm{~g}$; leaf area and dry mass were then used to calculate leaf mass per unit area $\left(\mathrm{mg} \mathrm{mm}^{-2}\right)$ for each tree. To characterize species WD $\left(\mathrm{g} \mathrm{cm}^{-3}\right)$, which is more laborious, we sampled three branches (diameter 1-2 cm) from each corresponding individual that was sampled for leaf traits $(12,348$ branches in total). We removed the pith, phloem and bark, measured fresh volume on the rest of the branch using water displacement and determined dry mass after drying for $72 \mathrm{hr}$ at $70^{\circ} \mathrm{C}$ (Cornwell et al., 2006). Branch density is the dry mass of the rest of the branch (minus the pith, phloem, and bark) divided by its volume, and has been demonstrated to be closely related to core stem density for adult trees in BNR $\left(R^{2}=0.93\right.$; Bu et al., 2014).

We measured environmental characteristics in each $5 \mathrm{~m} \times 5 \mathrm{~m}$ quadrat including soil organic matter $\left(\mathrm{g} \mathrm{kg}^{-1}\right)$, total and available phosphorus ( $\mathrm{g} \mathrm{kg}^{-1}$ and $\mathrm{mg} \mathrm{kg}^{-1}$ respectively), and total and 
available nitrogen ( $\mathrm{g} \mathrm{kg}^{-1}$ and $\mathrm{mg} \mathrm{kg}^{-1}$ respectively). Three soil cores ( $4 \mathrm{~cm}$ in diameter and $20 \mathrm{~cm}$ in depth) were collected in each $5 \mathrm{~m} \times 5 \mathrm{~m}$ quadrat. The three soil samples were evenly mixed and air-dried, and then were ground to a fine powder with a mill. Finally, samples were hand-sieved, and analyzed according to Agricultural Chemistry Committee of Soil Society of China (1983) (Appendices S2 and S4). In total, 768 mixed soil samples were obtained for the $4820 \mathrm{~m} \times 20 \mathrm{~m}$ plots.

\section{3 | Data analyses}

\subsection{1 | Trait relationships across tree individuals, species and communities}

Leaf mass area values at the individual level were calculated as the average of three sampled leaves per individual plant and individual WD values were calculated as the mean of the three branch samples taken per individual. Species-level values for each trait were calculated as the mean of all sampled individual plants per recorded species. Plot-level values for each trait (among species) were calculated as the abundance-weighted mean trait values for each $20 \mathrm{~m} \times 20 \mathrm{~m}$ plot (abundance $=$ number of individual plants) and represent the mean community-level trait values (Long, Zang, Schamp, et al., 2011). All trait values were $\log _{10}$-transformed to normalize strongly positively skewed distributions.

Bivariate relationships among LMA, $\mathrm{H}$ and WD were explored at the individual, species and community levels. Thus, we examined three trait pairs, using regression analyses at each level (nine bivariate relationships in total). When calculating the within-species trait relationships, we quantified bivariate relationships for each trait pair for each species using type II regression as there are no independent or dependent variables and measurement error exists for all traits. We calculated each within-species slope using the standardized major axis approach using the "sma" function in the SMATR package in R. We used Student's $t$ tests to determine whether all the within-species slopes differed significantly from zero. The single slope value for each trait pair at the individual-level bivariate relationship was calculated as the mean of all individual species slopes. Among the 174 species investigated, 98 species had over six individuals in the 1.92 ha study areas. Consequently, these species (3,920 individuals) were considered for individual-level trait relationships. When calculating the species- and community-level trait relationships, we also quantified bivariate relationships and slopes of type II regression using the standardized major axis approach. We tested whether these species- and community-level regression slopes differed from +1 or -1 using the sma function (with slope.test $=+1$ or -1 ).

Again using the sma function, we tested whether the bivariate trait relationships across individual, species and community levels shared a common slope, with the individual, species and community level as group factors.

\subsubsection{Effects of soil conditions on trait relationships}

Five soil variables, including organic matter, total and available phosphorus and nitrogen, were measured in each of our $5 \mathrm{~m} \times 5 \mathrm{~m}$ quadrats, and were accepted as reflecting the soil conditions relevant to the growth of trees in those quadrats. These soil measures were averaged across plots associated with each species to represent the soil conditions specific to each species. The community-level soil conditions were calculated as the mean of each soil factor within each $20 \mathrm{~m} \times 20 \mathrm{~m}$ plot (i.e., mean values in $165 \mathrm{~m} \times 5 \mathrm{~m}$ quadrats).

We then assessed the effects of the soil variables on trait relationships using multiple regressions, with one trait serving as the response variable, and with all soil variables as well as a second trait serving as explanatory variables (five explanatory variables in each multiple regression). To understand whether soil variables altered the relationship between the two traits, we examined the standardized regression coefficients for each soil variable. If the significant standardized coefficients for soil variables were positive or negative, the corresponding variables were interpreted as positively or negatively affecting the bivariate trait relationships. All the data were analyzed in the R 3.1.1 environment ( $R$ Core Development Team, 2014).

\section{3 | RESULTS}

\section{1 | Trait relationships across three hierarchical scales}

For the 3,920 individual trees, $\mathrm{H}$ ranged from 1 to $21 \mathrm{~m}$, and the average height was $7.05 \mathrm{~m}$. LMA ranged from $0.001 \mathrm{mg} \mathrm{mm}^{-2}$ to $0.079 \mathrm{mg} \mathrm{mm}^{-2}$, and the average was $0.012 \mathrm{mg} \mathrm{mm}^{-2}$. WD ranged from 0.20 to $0.98 \mathrm{~g} \mathrm{~cm}^{-3}$, and the average WD was $0.56 \mathrm{~g} \mathrm{~cm}^{-3}$.

Although trait relationships varied in strength, LMA-H, LMAWD and H-WD were positively related at the individual, species and community level (Table 1; Figure 1). SMA slopes of these bivariate relationships were generally disproportionate (i.e., differed significantly from +1 or -1 ). Moreover, for each bivariate relationship, there were no significant differences in SMA slopes across these three scales (Table 1; SMA tests: LMA-H, $p=0.06$; LMAWD, $p=0.35 ; \mathrm{H}-\mathrm{WD}, p=0.20$ ), suggesting similar relationships at the individual, species and community level for each trait pair.

\subsection{Effects of soil variables on trait relationships across the three hierarchical scales}

The slopes of the LMA-H, LMA-WD and H-WD relationships across all three hierarchical scales generally increased significantly with soil phosphorus, whereas nitrogen only affected the individual and 
TAB LE 1 Bivariate relationships for leaf mass per area (LMA), plant height (H) and wood density (WD) across individuals $(n=3,920)$, species $(n=98)$ and communities $(n=48)$

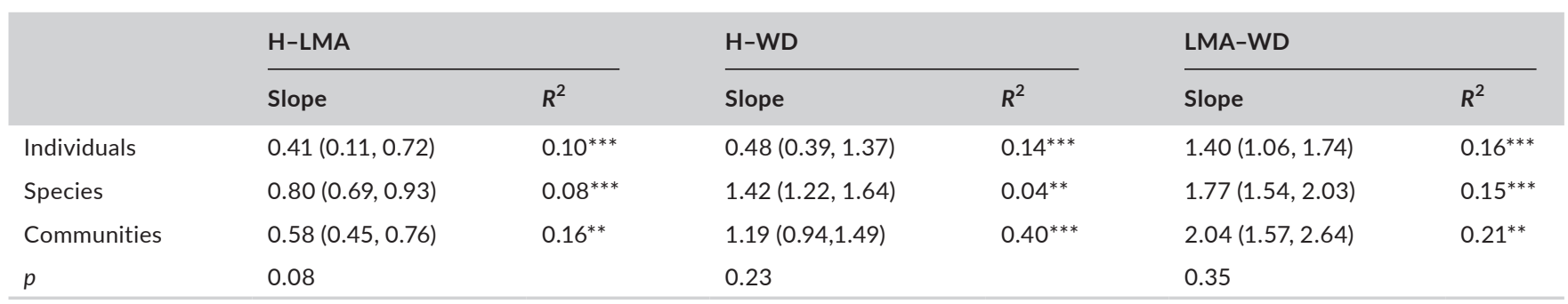

Standardized major axis (SMA) slope, 95\% confidence interval (in parentheses), coefficient of determination $\left(R^{2}\right)$ and significance level (indicated by asterisks) are shown. The first variable mentioned is the $\mathrm{Y}$ variable (e.g., $\mathrm{H}$ ) and the second variable mentioned is the $\mathrm{X}$ variable (e.g., $\mathrm{LMA}$ ). Each trait was $\log _{10}$-transformed before analysis. Differences in SMA slopes across the individual, species and community levels were assessed using a SMA function in $\mathrm{R}$ software and the corresponding $p$ value is given in the bottom row.

${ }^{* *} p<0.01$.

${ }^{* * *} p<0.001$

community-scale relationships, and organic matter only affected the individual and species-scale relationships (Table 2).

\section{4 | DISCUSSION}

\section{1 | Positive trait-scaling relationships in tropical cloud forests}

We found, as expected, positive relationships between LMA and $\mathrm{H}, \mathrm{LMA}$ and WD and $\mathrm{H}$ and WD at all three organizational scales (Figure 1; Table 1). High LMA is related to a plant's ability to resist physical stress, enhance leaf longevity and conserve nutrients (Castro-Díez, 2012). The positive correlation between LMA and H indicates that sun- or wind-exposed tree species make thicker and/ or denser leaves to enhance light capture (Gutschick and Wiegel, 1988; Long, Schamp et al., 2015) and resist physical stress.

High WD enhances the stiffness and strength of wood, thus protecting trees against biophysical hazards and enhancing plant survival (van Gelder et al., 2006). Positive correlations between WD and $\mathrm{H}$ indicate that taller trees in tropical cloud forests have denser wood, likely to avoid buckling due to self-loading and stem breakage that can result from strong winds.

Positive correlations between LMA and WD indicate that under particular conditions, trees in tropical cloud forests employ a resource conservation strategy that enhances both leaf and stem toughness and persistence. For example, plants in low soil phosphorus environments in tropical cloud forests may employ a conservative resource use strategy to accumulate relatively more carbon-rich chemicals in leaves and wood (i.e., high LMA and WD; Niinemets and Kull, 2003; Pérez-Harguindeguy et al., 2013). This increases the lignin and carbon density of the cell wall, contributing to the thickening and hardening of those walls, thus enhancing the longevity of stem and leaves as well as the nutrient residence time in the plant. The disproportionate scaling relationship between LMA and WD may also be mediated by plant height, as taller trees are more exposed to wind and have higher WD and LMA.
Similar positive relationships for these traits have been found across species (Fonseca et al., 2000; Chave et al., 2009; Long, Zang, Schamp, et al., 2011; Pérez-Harguindeguy et al., 2013). However, Falster and Westoby (2005) found a negative relationship between WD and maximum species height for tropical rain-forest species. In those rain-forest understories, it is possible that high WD protects against pathogens and falling debris, helping trees avoid tissue loss and enhancing survival and shade tolerance (Alvarez-Clare and Kirajima, 2007). In cloud forests, trees are small in stature (less than $5 \mathrm{~m}$ tall), long-lived and light-demanding (Long, Zang, and Ding, 2011), and their higher wood density is clearly beneficial to survival in strong winds and high sun (Peterson, 2000; Poorter, 2008; Thomas et al., 2015).

\section{2 | Disproportionate scaling relationships across the three hierarchical scales}

As hypothesized, tropical cloud forest trees showed disproportionate scaling relationships between LMA and H, LMA and WD and $H$ and WD, across the individual, species and community levels (Table 1). The slopes of bivariate trait relationships (on log-log axes), also called "scaling exponents," indicate the proportionality or disproportionality of resource allocation to different plant functions. The fact that scaling components of the three trait pairs we studied differed significantly from one (Table 1 ) indicates unique allocation strategies for tropical cloud forest trees. For example, a $10 \%$ increase in $\mathrm{H}(\log )$ co-incided with an increase in LMA (log) of $25 \%$ at the individual level, $13 \%$ at the species level and $17 \%$ at the community level. The same increase in $\mathrm{H}$ also co-incided with an increase in WD (log) of $5 \%$ at the individual level, $14 \%$ at the species level, and $12 \%$ at the community level (Figure 1). Thus, we can see that for a given gain in carbon, resource investment at the species and community levels is higher in stem WD than in stem $\mathrm{H}$. Differences in material investments between $\mathrm{H}$ and WD probably show that resistance to strong wind stresses is more important than competition for light for tropical cloud forest trees. Thus, our results show that trait 

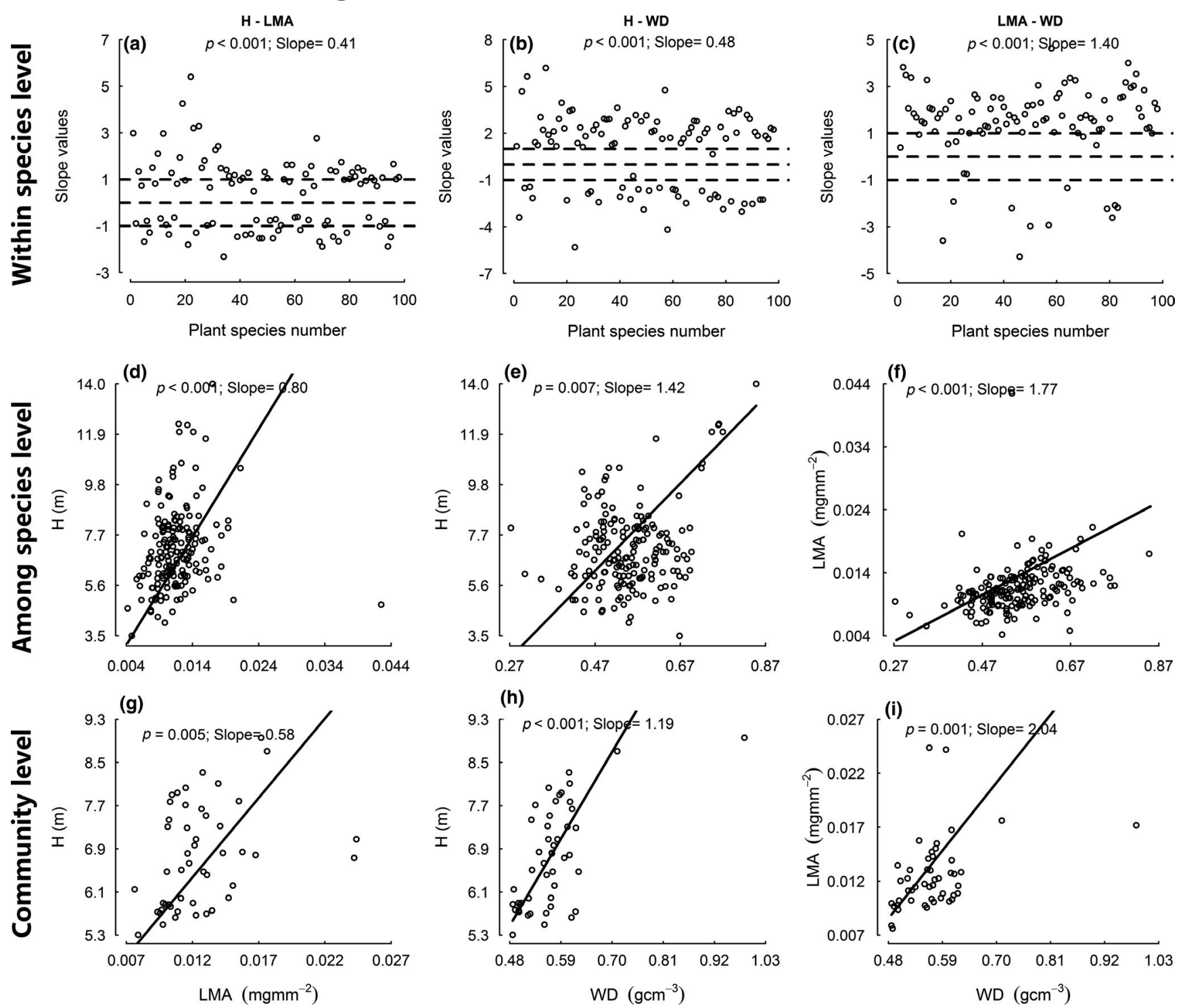

(h)
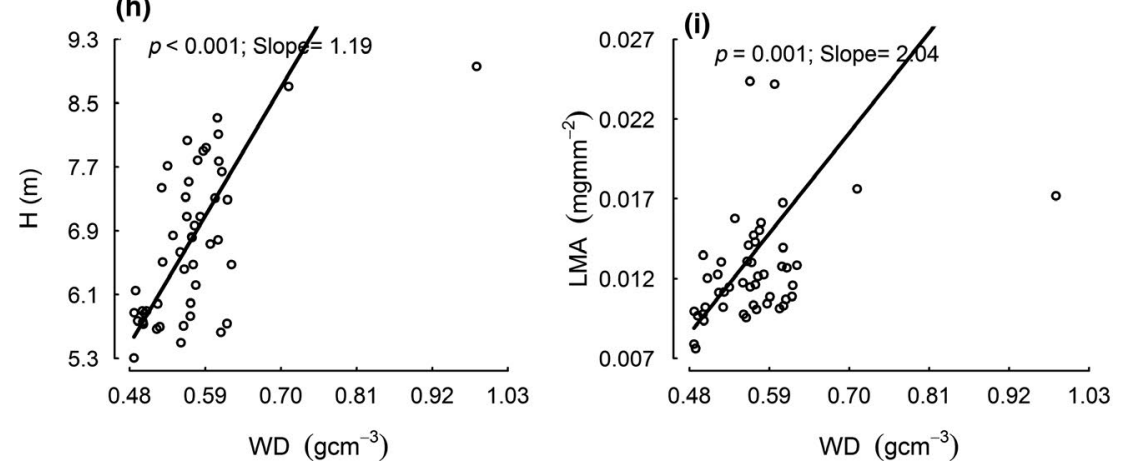

FIGURE 1 Mean standardized major axis (SMA) slopes for (a, d, g) plant height (H) and leaf mass per area (LMA), (b, e, h) H and wood density (WD), (c, f, i) LMA and WD across within-species (a-c), among-species (d-f) and community levels ( $g$-i). The slope values in panels a-c were calculated as the mean value for each trait pair across all species at the within-species level, and the $p$ value was derived from a Student's $t$ test which determines whether slopes differed significantly from zero. The slope values and $p$ values in panels $d$-i derived from those in the SMA analyses. The dashed horizontal lines in panels a-c indicate slopes equal to +1 and -1 . Each trait was $\log _{10}$-transformed before analysis

functional relationships can vary across tropical systems, and differences between our results and those from lowland tropical forests are most likely driven by differences in environmental stresses in the two systems. In tropical cloud forests, trees are regularly exposed to high winds, which may explain the small stature of trees in these forests (Long, Zang, Schamp, et al., 2011).

Our findings reinforce that these three functional trait pairs represent core plant strategies for maximizing growth while tolerating the environmental stresses in tropical cloud forests (i.e., low soil phosphorus and strong winds). One potential explanation for similar trait relationships across the three levels is that phosphorus is a limiting nutrient in this system, affecting the resource strategies of individuals, species and communities in similar ways (Table 2). Our results support the general view that these functional traits, along with other unmeasured but correlated functional traits, capture primary dimensions of functional variation (Witkowski and Lamont, 1991; Wright et al., 2004; Poorter et al., 2009; Baraloto et al., 2010; Grady et al., 2013).

The similar scaling relationships for each trait pair across the individual, species and community levels (Table 1), suggest that there is a similar allocation strategy operating across hierarchical scales. The within-species bivariate relationships for some species, however, have negative slopes (Figure $1 \mathrm{a}-\mathrm{c}$ ). This suggests that these scaling relationships are highly variable, and may be constrained under particular environmental conditions (e.g., air temperature; Long, Zang, and Ding, 2011). Tree species in tropical cloud forests 


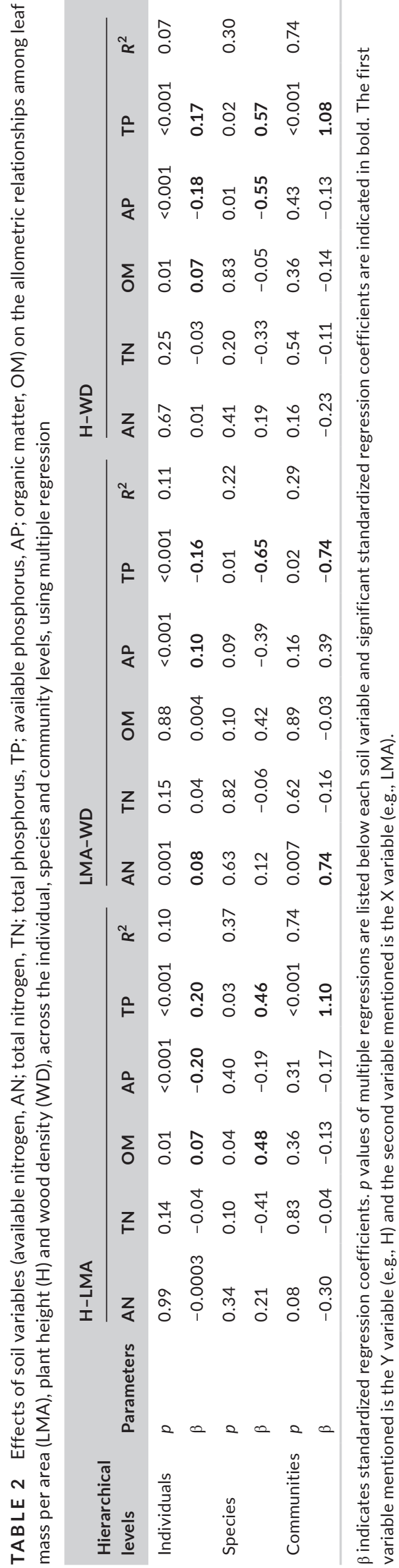

have a high structural plasticity to cope with variable environments (Long, Zang, and Ding, 2011), and thus may show a fairly flexible allocation strategy responding to temperature constraints. Trait variation at the individual and community levels is comparable to species-level variation (Wright et al., 2004; Chave et al., 2009), indicating that they are likely to be important for plant and community performance (Albert et al., 2010; Bolnich et al., 2011; Long, Zang, Schamp, et al., 2011; Laforest-Lapointe et al., 2014). Additionally, our findings show that scale choice for investigating these bivariate relationships may be less important for some of these three trait pairs than for others.

Although our results suggest similar trait relationships across the three hierarchical levels, the slopes of bivariate relationships of the three trait pairs at the species level were consistently, although not significantly, steeper than at the individual level (Table 1). This suggests that stronger variation in plant allocation strategies is possible at the species level than at the individual level (e.g., species can vary more markedly in maximum $\mathrm{H}$ and WD than individuals within species), as species come from different phylogenetic origins and can display a wide range of strategies. Another explanation for the differences in scaling slopes between the individual and species levels in this study may be that the intra- and interspecific level analysis occurs across different portions of environmental gradients because individual trees and species occupy different parts of the prevailing gradients. That is, the selection pressure that shapes differential resource allocation to these traits at the within-species level might differ from those at the among-species level. For the community-level analysis, however, community-weighted values for pairs of traits are not fully independent as abundance weightings are used for both variables. This issue can inflate $p$ values and impact interpretations. We interpreted these analyses with caution, and focused on slopes, rather than the significance of the relationships (Zeleny, 2018).

\subsection{Soil nutrient effects on scaling relationships}

Interestingly, we found that the LMA-H, WD-H and LMA-WD relationships across all three hierarchical levels were modified by soil phosphorus. The individual- and community-scale relationships were also affected by soil nitrogen, and the individual and species-scale relationships were significantly impacted by organic matter levels (Table 2). In tropical forests, nitrogen is thought to limit plant performance (Santiago et al., 2012); however, these tropical cloud forests grow on strongly weathered soils, where rock-derived nutrients such as phosphorus are limiting (Table 2; Vitousek et al., 2010). The significant effects of soil phosphorus on trait relationships in this study suggest that soil phosphorus may act as an important determinant of variation in LMA, $\mathrm{H}$ and WD at the individual, species and community levels. This leads to slow-growing individual trees and species with low LMA, high $\mathrm{H}$, and high WD values that are favored under the low soil phosphorus conditions in tropical cloud forests. Additionally, the similar 
resource allocation strategies across the individual, species and community levels observed here are responsive to multiple abiotic stresses such as low soil phosphorus, (Table 2; Long et al., 2013; Long, Schamp, et al., 2015, Long, Xiong, et al., 2015). Similar spectra in resource use strategies across these three levels may help forest trees partition the phosphorus gradient and persist under this environmental constraint. That is, the positive effect of $\mathrm{P}$ on the $\mathrm{H}$-LMA slope may indicate that plants in tropical cloud forests preferentially invest in $\mathrm{H}$ over LMA at high soil $\mathrm{P}$, to capture more light and grow faster. The positive effect of $P$ on the $\mathrm{H}-\mathrm{WD}$ slope, as well as the negative effect of $\mathrm{P}$ on the LMA-WD slope, however, may indicate that plants in tropical cloud forests invest in high WD over $\mathrm{H}$ and LMA to resist strong wind stresses. Additionally, this scaling relationship adds evidence of a strategy of disproportional nutrient allocation between leaf and stem as a means of adapting to stress related to low soil phosphorus. That is, woody biomass could provide a well-defended storage organ for phosphorus (Chapin et al., 1990), whereas leaves are a poorer storage organ due to their relatively short lifespan and increased vulnerability to herbivores. This resource use strategy most likely enables trees in tropical cloud forests to store two times more phosphorus in wood than in leaves, promoting the nutrient use efficiency of trees, and enhancing their survival in these tropical forests. We also found that the effects of total and available phosphorus on trait relationships were opposite (Table 2). This probably results from the fact that there is a negative relationship between total and available phosphorus (Appendix S4). For example, there was no clear difference in total phosphorus between BNR and JNR ( $p=0.06$ ), while available phosphorus in BNR was significantly higher than in JNR (BNR, $16.85 \pm 7.15$; JNR, $1.06 \pm 1.18 ; p<0.001$ ). The differences in available phosphorus between BNR and JNR may be due to the observed higher topographic slopes for forest plots in JNR compared to BNR. Steep slopes may allow soil clay components with rich soil mineral (e.g., available phosphorus) in JNR to be lost downslope, reducing the available components in soils. Large changes in available soil components with plot slope suggest that this parameter may poorly represent soil conditions in tropical cloud forests.

Finally, species co-occurrence patterns in these systems, which have been linked to facilitation, are accentuated in low soil phosphorus conditions (Long, Xiong, et al., 2015). As such, trees species in these environments have likely evolved a common strategy for dealing with low phosphorus conditions that is successful relative to allocation by other species (Field and Mooney, 1986). This co-evolution increases survival chances not only for individual trees, but for tree species and even the whole community. Trees in competitive environments, however, may not experience a similar co-evolutionary pathway, particularly if functional traits under selection become divergent (i.e., niche differentiation). This may be one reason that consistent scaling relationships across different hierarchical levels are not more commonly observed in natural systems (e.g., Ackerly et al., 2002; Domínguez et al., 2012).

\section{5 | Conclusions}

We found positive relationships for LMA-H, LMA-WD and H-WD. Relationships between the three trait pairs were disproportionate, suggesting differential resource investments between $H$ and WD and LMA. The disproportionate scaling relationship between stem density and stem height suggests that resource investment is higher in stem density than stem height, which indicates that resistance to strong wind stresses is a primary driver of resource allocation patterns in tropical cloud forests (Thomas et al., 2015). The scaling components for the studied trait pairs were statistically similar across the individual, species and community levels, suggesting a similar allocation strategy operating at different hierarchical levels. Finally, we found that scaling relationships across all three hierarchical scales are strongly affected by soil phosphorus. This suggests that resource allocation patterns for these important functional traits, which define important plant strategies, are driven by a combination of extreme conditions related to solar irradiance and soil nutrient levels.

\section{ACKNOWLEDGEMENT}

We thank Rucai Li and Qing Chen for their assistance in fieldwork.

\section{AUTHOR CONTRIBUTIONS}

$\mathrm{WL}, \mathrm{YZ}$ and RZ conceived the ideas and designed methodology; WL and $M X$ collected the data; $W L$ and BSS analyzed the data; WL, BSS, $X Y$, LP and CX led the writing of the manuscript. All authors contributed critically to the drafts and gave final approval for publication.

\section{DATA AVAILABILITY STATEMENT}

The data supporting the findings of this study are stored at the Data center of the College of Forestry and are available in Appendices S1, S2, S3 and S4.

\section{ORCID}

Brandon S. Schamp iD https://orcid.org/0000-0002-6885-2029

\section{REFERENCES}

Ackerly, D.D., Knight, C.A., Weiss, S.B., Barton, K., \& Starmer, K.P. (2002). Leaf size, specific leaf area and microhabitat distribution of chaparral woody plants: contrasting patterns in species level and community level analyses. Oecologia, 130, 449-457. https://doi.org/10.1007/ s004420100805.

Agricultural Chemistry Committee of Soil Society of China, (Eds.) (1983). Agricultural Chemical Routine Analysis Methods of Soil. Beijing, China: Science Press.

Albert, C.H., Thuiller, W., Yoccoz, N.G., Douzel, R., Aubert, S., \& Lavorel, S. (2010). A multi-trait approach reveal the structure and the relative importance of intra- vs. interspecific variability in plant traits. Functional Ecology, 24, 1129-1201. https://doi. org/10.1111/j.1365-2435.2010.01727.x.

Alvarez-Clare, S., \& Kitajima, K. (2007). Physical defence traits enhance seedling survival of neotropical tree species. Functional Ecology, 21, 1044-1054.

Baraloto, C., Paine, C.E.T., Poorter, L., Beauchene, J., Bonal, D., Domenach, A.M. ... et al (2010). Decoupled leaf and stem economics 
in rain forest trees. Ecology Letters, 13, 1338-1347. https://doi. org/10.1111/j.1461-0248.2010.01517.x.

Bolnich, D.I., Amarasekare, P., Araújo, M.S., Bürger, R., Levine, J.M., Novak, M. ... et al (2011). Why intraspecific trait variation matters in community ecology. Trends in Ecology and Evolution, 26, 183-192. https://doi.org/10.1016/j.tree.2011.01.009.

Bu, W.S., Zang, R.G., \& Ding, Y. (2014). Field observed relationship between biodiversity and ecosystem functioning during secondary succession in a tropical lowland rainforest. Acta Oecologica, 55, 1-7. https://doi.org/10.1016/j.actao.2013.10.002.

Castro-Díez, P. (2012). Functional traits analyses: scaling-up from species to community level. Plant and Soil, 357, 9-12. https://doi. org/10.1007/s11104-012-1185-8.

Chapin, F.S., Schulze, E.D., \& Mooney, H.A. (1990). The ecology and economics of storage in plants. Annual Review of Ecology and Systematics, 21, 423-447. https://doi.org/10.1146/annurev.es.21.110190.002231.

Chave, J., Coomes, D., Jansen, S., Lewis, S.L., Swenson, N.G., \& Zanne, A.E. (2009). Towards a worldwide wood economics spectrum. Ecology Letters, 12, 351-366.

Cornwell, W.K., Schwilk, D.W., \& Ackerly, D.D. (2006). A trait-based test for habitat filtering: convex hull volume. Ecology, 87, 1465-1471. https://doi.org/10.1890/0012-9658.

Cornwell, W.K., \& Ackerly, D.D. (2009). Community assembly and shifts in plant trait distributions across an environmental gradient in coastal California. Ecological Monographs, 79, 109-126. https://doi. org/10.1890/07-1134.1.

de Bello, F., Carmona, C.P., Mason, N.W.H., Sebastià, M.T., \& Lepš, J. (2013). Which trait dissimilarity for functional diversity: Trait means or trait overlap? Journal of Vegetation Science, 24, 807-819. https:// doi.org/10.1111/jvs.12008.

Domínguez, M.T., Aponte, C., Pérez-Ramos, I.M., García, L.V., Villar, R., \& Marañón, T. (2012). Relationships between leaf morphological traits, nutrient concentrations and isotopic signatures for mediterranean woody plant species and communities. Plant \& Soil, 357, 407-424. https://doi.org/10.1007/s11104-012-1214-7.

Díaz, S., Kattge, J., Cornelissen, J.H.C., Wright, I.J., Lavorel, S., Dray, S. ... et al (2016). The global spectrum of plant form and function. Nature, 529, 167-171.

Editorial Committee of Flora of China (Eds.) (2004). Flora Reipublicae Popularis Sinicae (Chinese edition of Flora of China). Beijing, China: Science Press.

Falster, D.S., \& Westoby, M. (2005). Alternative height strategies among 45 dicot rain forest species from tropical Queensland, Australia. Journal of Ecology, 93, 521-535. https://doi. org/10.1111/j.0022-0477.2005.00992.x.

Falster, D.S., \& Westoby, M. (2003). Plant height and evolutionary games. Trends in Ecology and Evolution, 18, 337-343. https://doi. org/10.1016/S0169-5347(03)00061-2.

Field, C., \& Mooney, H.A. (1986).Photosynthesis-nitrogen relationship in wild plants. On the Economy of Plant Form and Function: Proceedings of the Sixth Maria Moors Cabot Symposium, Evolutionary Constraints on Primary Productivity, Adaptive Patterns of Energy Capture in Plants, Harvard Forest, August (pp. 25-55).

Fonseca, C.R., Overton, J.M.C., Collins, B., \& Westoby, M. (2000). Shifts in trait-combinations along rainfall and phosphorus gradients. Journal of Ecology, 88, 964-977. https://doi. org/10.1046/j.1365-2745.2000.00506.x.

Grady, K.C., Laughlin, D.C., Ferrier, S.M., Kolb, T.E., Hart, S.C., Allan, G.J., et al (2013). Conservative leaf economic traits correlate with fast growth of genotypes of a foundation riparian species near the thermal maximum extent of its geographic range. Functional Ecology, 27, 428-438. https://doi.org/10.1111/1365-2435.12060.

Gutschick, V.P., \& Wiegel, F.W. (1988). Optimizing the canopy photosynthetic rate by patterns of investment in specific leaf mass. American Naturalist, 132, 67-86. https://doi.org/10.1086/284838.
Jensen, A.M., Schamp, B.S., \& Belleau, A. (2019). Evidence of temporal niche separation via low flowering time overlap in an old-field plant community. Oecologia, 189, 1071-1082. https://doi.org/10.1007/ s00442-019-04386-0.

Laforest-Lapointe, I., Martínez-Vilalta, J., \& Retana, J. (2014). Intraspecific variability in functional traits matters: case study of Scots pine. Oecologia, 175(4), 1337-1348. https://doi.org/10.1007/s0044 2-014-2967-x.

Long, W., Ding, Y., Zang, R., Yang, M., \& Chen, S.W. (2011). Environmental characteristics of tropical cloud forests in the rainy season in Bawangling National Natural Reserve on Hainan Island, South China. Chinese Journal of Plant Ecology, 35, 137-146.

Long, W., Schamp, B.S., Zang, R., Ding, Y., Huang, Y.F., \& Xiang, Y.Z. (2015). Community assembly in a tropical cloud forest related to specific leaf area and maximum species height. Journal of Vegetation Science, 26, 513-523. https://doi.org/10.1111/jvs.12256.

Long, W., Xiong, M., Zang, R., Schamp, B.S., Yang, X., Ding, Y., et al (2015). Changes in patterns of species co-occurrence across two tropical cloud forests differing in soil nutrients and air temperature. Biotropica, 47, 416-423. https://doi.org/10.1111/btp.12235.

Long, W., Zang, R., \& Ding, Y. (2011). Air temperature and soil phosphorus availability correlate with trait differences between two types of tropical cloud forests. Flora, 206, 896-903. https://doi. org/10.1016/j.flora.2011.05.007.

Long, W., Zang, R., Schamp, B.S., \& Ding, Y. (2011). Within- and among-species variation in specific leaf area drive community assembly in a tropical cloud forest. Oecologia, 167, 1103-1113. https://doi. org/10.1007/s00442-011-2050-9.

Long, W., Zang, R.G., Ding, Y., \& Huang, Y.F. (2013). Effects of competition and facilitation on species assembly in two types of tropical cloud forest. PLoS ONE, 8, e60252.

Messier, J., McGill, B.J., Enquist, B.J., \& Lechowicz, M.J. (2017). Trait variation and integration across scales: is the leaf economic spectrum present at local scales? Ecography, 40, 685-697. https://doi. org/10.1111/ecog.02006.

Niinemets, Ü., \& Kull, K. (2003). Leaf structure vs. nutrient relationships vary with soil conditions in temperate shrubs and trees. Acta Oecologica, 24, 209-219. https://doi.org/10.1016/S1146 $-609 \times(03) 00094-8$.

Onoda, Y., Westoby, M., Adler, P.B., Choong, A.M.F., Clissold, F.J., Cornelissen, J.H.C., et al (2011). Global patterns of leaf mechanical properties. Ecology Letters, 14, 301-312. https://doi. org/10.1111/j.1461-0248.2010.01582.x.

Pérez-Harguindeguy, N., Díaz, S., Garnier, E., Lavorel, S., Poorter, H., Jaureguiberry, P. et al (2013). New handbook for standardised measurement of plant functional traits worldwide. Australian Journal of Botany, 61, 167-234.

Peterson, C.J. (2000). Catastrophic wind damage to North American forests and the potential impact of climate change. Science of the Total Environment, 262, 287-311. https://doi.org/10.1016/S0048 -9697(00)00529-5.

Poorter, H., Niinemets, Ü., Poorter, L., Wright, I.J., \& Villar, R. (2009). Causes and consequences of variation in leaf mass per area (LMA): a meta-analysis. New Phytologist, 182, 565-588. https://doi. org/10.1111/j.1469-8137.2009.02830.x.

Poorter, L. (2008). The relationships of wood-, gas- and water fraction of tree stems to performance and life history variation in tropical trees. Annals of Botany, 102, 367-375. https://doi.org/10.1093/aob/ men103.

Price, C.A., \& Weitz, J.S. (2012). Allometric covariation: a hallmark behavior of plants and leaves. New Phytologist, 193, 882-889. https:// doi.org/10.1111/j.1469-8137.2011.04022.x.

R Core Development Team (Ed.) (2014). R: A Language and Environment for Statistical Computing. Vienna, Austria: R Foundation for Statistical Computing. 
Reich, P.B., Walters, M.B., \& Ellsworth, D.S. (1997). From tropics to tundra: global convergence in plant functioning. Proceedings of the National Academy of Science, 94, 13730-13734. https://doi. org/10.1073/pnas.94.25.13730.

Reich, P.B. (2014). The world-wide 'fast-slow' plant economics spectrum: a trait manifesto. Journal of Ecology, 102, 275-301.

Santiago, L.S., Wright, S.J., Harms, K.E., Yavitt, J.B., Korine, C., Garcia, M.N., et al (2012). Tropical tree seedling growth response to nitrogen, phosphorus and potassium addition. Journal of Ecology, 100, 309-316. https://doi.org/10.1111/j.1365-2745.2011.01904.x.

Siefert, A., Violle, C., Chalmandrier, L., Albert, C.H., Taudiere, A., Fajardo, A. et al (2015). A global meta-anlysis of the relative extent of intraspecific trait variation in plant communities. Ecology Letters, 18, 1406-1419. https://doi.org/10.1111/ele.12508.

Swenson, N.G., \& Weiser, M.D. (2010). Plant geography upon the basis of functional traits: an example from eastern North American trees. Ecology, 91, 2234-2241. https://doi.org/10.1890/09-1743.1.

Thomas, S.C., Martin, A.R., \& Mycroft, E.E. (2015). Tropical trees in a wind-exposed island ecosystem: height-diameter allometry and size at onset of maturity. Journal of Ecology, 103, 594-605. https://doi. org/10.1111/1365-2745.12378.

van Gelder, H.A., Poorter, L., \& Sterck, F.J. (2006). Wood mechanics, allometry, and life-history variation in a tropical rain forest tree community. New Phytologist, 171, 367-378. https://doi. org/10.1111/j.1469-8137.2006.01757.x.

Vasseur, F., Violle, C., Enquist, B., Granier, C., \& Vile, D. (2012). A common genetic basis to the origin of the leaf economics spectrum and metabolic scaling allometry. Ecology Letters, 15, 1149-1157. https://doi. org/10.1111/j.1461-0248.2012.01839.x.

Vitousek, P.M., Porder, S., Houlton, B.Z., \& Chadwick, O.A. (2010). Terrestrial phosphorus limitation: mechanisms, implications, and nitrogen-phosphorus interactions. Ecological Applications, 20, 5-15.

Westoby, M. (1998). A leaf-height-seed (LHS) plant ecology strategy scheme. Plant and Soil, 199, 213-227.

Witkowski, E.T.F., \& Lamont, B.B. (1991). Leaf specific mass confounds leaf density and thickness. Oecologia, 88, 486-493. https://doi. org/10.1007/BF00317710.

Wright, I.J., Reich, P.B., Westoby, M., Ackerly, D.D., Baruch, Z., Bongers, F. ...et al (2004). The worldwide leaf economics spectrum. Nature, 428, 821-827. https://doi.org/10.1038/nature02403.
Wright, J.P., \& Sutton-Grier, A. (2012). Does the leaf economic spectrum hold within local species pools across varying environmental conditions? Functional Ecology, 26, 1390-1398. https://doi. org/10.1111/1365-2435.12001.

Xiang, S.X., Reich, P.B., Sun, S.C., \& Atkin, O.K. (2013). Contrasting leaf trait scaling relationship in tropical and temperate wet forest species. Functional Ecology, 27, 522-534. https://doi. org/10.1111/1365-2435.12047.

Zelený, D. (2018). Which results of the standard test for community-weighted mean approach are too optimistic? Journal of Vegetation Science, 29(6), 953-966.

\section{SUPPORTING INFORMATION}

Additional supporting information may be found online in the Supporting Information section.

Appendix S1. Dominant tree species and individual number in the tropical cloud forest plots of the Bawangling Nature Reserve (BNR), Jianfengling Nature Reserve (JNR) and Limushan Nature Reserve (LNR) on Hainan Island, Southern China

Appendix S2. The mean soil nutrient contents of 48 tropical cloud forest plots in Bawangling Nature Reserve (BNR), Jianfengling Nature Reserve (JNR) and Limushan Nature Reserve (LNR)

Appendix S3. The mean values for each species of the height, leaf mass per area and wood density measured in tropical cloud forests

Appendix S4. Correlations among the five soil factors and methods of soil measurements in tropical cloud forests

How to cite this article: Long W, Zhou Y, Schamp BS, et al. Scaling relationships among functional traits are similar across individuals, species, and communities. J Veg Sci. 2020;31:571-580. https://doi.org/10.1111/jvs.12893 